J. Med. Microbiol.-Vol. 21 (1986), 87-90

(C) 1986 The Pathological Society of Great Britain and Ireland

\title{
Characterisation of mouse monoclonal antibodies produced by immunisation with a single serotype component of a polyvalent Pseudomonas aeruginosa vaccine
}

\author{
G. R. BARCLAY, P. L. YAP, D. B. L. McCLELLAND, R. J. JONES*, ELIZABETH A. ROE*, MOIRA C. \\ MCCANNT, LISEL R. MICKLEMT, AND K. JAMES ${ }^{\circ}$
}

Edinburgh and South-East Scotland Regional Blood Transfusion Centre, Royal Infirmary, Edinburgh, EH3 $9 H B,{ }^{*} M R C$ Vaccine Research Laboratories, Birmingham University Medical School, Birmingham, and †Department of Surgery, Edinburgh University, Edinburgh

\begin{abstract}
Summary. Mouse monoclonal antibodies raised by immunisation with a protective antigen extract from Pseudomonas aeruginosa serotype 1 varied in immunoglobulin isotype, in passive protective properties against infection by homologous $P$. aeruginosa serotype 1 , and in cross-reactions in ELISA against antigen preparations from 15 other $P$. aeruginosa serotypes. All monoclonal antibodies with specificity in ELISA for the immunising antigen gave some degree of protection to mice against lethal infection by the homologous $P$. aeruginosa serotype. The IgG antibodies were more protective than the IgM antibodies.
\end{abstract}

\section{Introduction}

A 16-part polyvalent pseudomonas extract vaccine (PEV) has been used for immunising burned patients against Pseudomonas aeruginosa in a prophylactic trial (Jones, 1979). It has also been shown that immunoglobulin from healthy volunteers immunised with PEV conferred passive immunity against pseudomonas septicaemia in severely burned children and in adults at risk from $P$. aeruginosa infection (Roe and Jones, 1983). PEV is composed of equal proportions of cellwall extracts from each of the 16 international serotypes of $P$. aeruginosa, pseudomonas vaccine antigens 1 to 16 (PVA-1 to PVA-16). The cell-wall extracts are predominantly lipopolysaccharide (Miler et al., 1977). Each elicited serotype-specific antibodies and a variable range of cross-reactive and cross-protective antibodies in mice (Jones and Roe, 1975).

To investigate the mechanism of protection against $P$. aeruginosa by passively transferred antibodies, mouse monoclonal antibodies were raised against one of the cell-wall extracts, PVA-1, extracted from $P$. aeruginosa strain B.UK.1 (serotype 1). These monoclonal antibodies were tested by ELISA for specificity and titre against the 16 extracts (PVA-1 to PVA-16) comprising PEV. Immunoglobulins in selected antipseudomonas clones were isotyped and their protective properties against homologous lethal challenge were determined in a mouse protection test.

\section{Materials and methods}

\section{Bacteria}

$P$. aeruginosa strain B.UK.1 (serotype 1) was isolated from the blood of a septicaemic burned patient at Birmingham Accident Hospital by routine methods

Received 13 Feb. 1985; accepted 19 Apr. 1985.
(Davis et al., 1969). Strains of the other 15 serotypes of $P$. aeruginosa used for preparing the PVAs incorporated in PEV were isolated from hospital sources in Europe, Asia and Japan. These bacteria were selected because their extracts caused minimal toxic reactions when used as vaccines in mice and rabbits (Miler et al., 1977).

\section{Extraction of PVA from cell walls}

Suspensions of the 16 serotypes of $P$. aeruginosa, each containing $(3-5) \times 10^{10}$ viable bacteria $/ \mathrm{ml}$, were grown for $16 \mathrm{~h}$ in a chemically defined medium and the PVAs were extracted by treatment for $2 \mathrm{~min}$ at $37^{\circ} \mathrm{C}$ with a mixture of $0.01 \mathrm{M}$ EDTA and $0.003 \mathrm{M}$ glycine according to the method of Miler et al. (1977). After mixing at room temperature with an equal volume of formaldehyde $0.6 \% \mathrm{w} / \mathrm{v}$ and positive pressure filtration through a membrane filter (Millipore, HA $0.65 \mu \mathrm{m})$, the crude soluble cell-wall extracts were lyophilised.

\section{Preparation of monoclonal antibodies}

Female 12-week-old BALB/c mice were immunised by three intraperitoneal injections, at weekly intervals, of $250 \mu \mathrm{g}$ of PVA-1 in $0.3 \mathrm{ml}$ of phosphate-buffered saline (PBS, $p$ H 7.2; Dulbecco "A", Oxoid). Antibody responses to PVAs 1-16 were determined by ELISA on serum obtained one week after the third dose. A mouse with a strong anti-PVA-1 response was immunised intravenously with $250 \mu \mathrm{g}$ of PVA-1 10 weeks after the third dose, and killed 3 days later to obtain spleen cells. Mouse spleen cells were fused with cells of the NS-1 (NS-1/1-Ag4-1) plasmacytoma cell line (Kohler et al., 1976) by the method of $\mathrm{Oi}$ and Herzenberg (1980). Selective and maintenance cultures were essentially as described by Kennett et al. (1979). Hybrids in HAT medium in 96-well c culture plates 
were screened for anti-PVA antibodies. Antibody-positive hybrids were cloned by limiting dilution.

\section{ELISA}

PVA stock solutions, $0 \cdot 1 \mathrm{mg} / \mathrm{ml}$ in distilled water, were diluted 1 in 100 in coating buffer $(0.1 \mathrm{M}$ carbonate-bicarbonate, $p \mathrm{H} \mathrm{9.6)}$ and placed (100 $\mu \mathrm{l} /$ well) in polystyrene 96-well microtitration plates ("Immulon" M129A, Dynatech, Billingshurst, Kent) for coating overnight at room temperature. All solutions were made in filtered distilled water containing sodium azide $0.1 \% \mathrm{w} / \mathrm{v}$. Plates were washed with PBS containing Tween-20 $0 \cdot 1 \% \mathrm{v} / \mathrm{v}$ (wash buffer), by an automated plate washer (Titertek "Multiwash", Flow Laboratories, Irvine, Scotland), incubated for a further $4 \mathrm{~h}$ at $37^{\circ} \mathrm{C}$ with bovine serum albumin $3 \% \mathrm{w} /$ $\mathrm{v}$ in PBS $(200 \mu \mathrm{l} /$ well), then washed again, rinsed in distilled water and stored at $4{ }^{\circ} \mathrm{C}$ until used. Culture supernates and antibodies were diluted in wash buffer containing polyethylene glycol $4 \%$ w/v (PEG 4000, Sigma) (dilution buffer). Culture supernates were screened at a 1 in 5 dilution in this buffer, and their titres determined by serial dilution. Volumes of 100 $\mu \mathrm{l} /$ well were incubated for $90 \mathrm{~min}$ at $37^{\circ} \mathrm{C}$ on coated plates, followed by four washes. Bound antibody was detected by the addition of urease-conjugated sheep anti-mouse immunoglobulins (Sera-Lab. Ltd, Crawley Down, Sussex) at a 1 in 200 dilution $(100 \mu \mathrm{l} /$ well) for $90 \mathrm{~min}$ at $37^{\circ} \mathrm{C}$. Unbound anti-mouse antibody was removed by washing four times. Plates were rinsed four times in distilled water and urease substrate solution (Sera-Lab) was added (100 $\mu \mathrm{l} /$ well). Specific antibody-positive reactions resulted in a change in substrate colour from yellow to blue (Chandler et al., 1982). The degree of reaction was determined after 90 min at $37^{\circ} \mathrm{C}$ by reading the optical density at $585 \mathrm{~nm}$ in an automated ELISA microplate reader (Titertek "Multiscan/MC", Flow Laboratories), and employing untreated substrate as a baseline reading (machine blank).

Immunoglobulin isotypes of monoclonal anti-pseudomonas antibodies were determined by double radial immunodiffusion in agar (Ouchterlony technique) with specific antibodies to each of mouse IgM, IgA, IgGI, IgG2a, IgG2b and IgG3 (Serotech Ltd, Bicester, Oxon). The IgG contents of supernates were measured by a modified Laurell-rocket technique, with known quantities of purified monoclonal IgG of appropriate subclasses as standards (C. Prowse and D.S. Pepper, unpublished). The IgM contents were measured by an anti-mouse IgM ELISA assay with a purified mouse monoclonal IgM as a standard.

\section{Passive protection tests}

Groups of five male CBA mice, each weighing c. 25 $\mathrm{g}$, were given intraperitoneal (ip) injections of $1.0 \mathrm{ml}$ of saline dilutions of monoclonal antibody (hybridoma supernates) at 1 in 10,1 in 50,1 in 100,1 in
200,1 in 400,1 in 1000,1 in 2000,1 in 5000 and 1 in 10000 . Two hours later, mice were challenged ip with 1.0 MLD of $P$. aeruginosa strain B.UK.1 according to previously described methods (Jones et al., 1971). The MLD which killed 5 out of 5 healthy control mice was $5.2 \times 10^{6} P$. aeruginosa B.UK.1. cells in $1 \mathrm{ml}$ of saline. After bacterial challenge, mice were given food and water ad libitum and the number of survivors recorded for the next 3 days.

\section{Results}

After fusion, 58 out of 153 hybrid cell cultures in selective medium secreted anti-PVA antibodies when screened by ELISA with each of the 16 serotype extracts. All 58 positive cultures secreted antibodies that reacted with the immunising antigen (PVA-1). Five of these 58 cultures also reacted with PVA-2 and PVA-12. A range of hybrids was selected for cloning by limiting dilution in maintenance culture medium. Selections were made of cultures with good growth characteristics and included those producing apparently multispecific (anti-PVA-1, -2 and -12) antibodies and a range of monospecific (anti-PVA-1) antibodies that gave different degrees of reaction in the ELISA screen.

A total of 18 hybrid cell lines secreting anti-PVA antibodies were obtained after cloning and maintenance through successive cultures. Each monoclonal antibody was characterised with regard to specificity for the 16 PVAs in ELISA, to ELISA titres against the antigens to which they showed specificities, to immunoglobulin isotype and to concentration in culture supernate. Each was tested for its capacity to protect mice against lethal challenge with the immunising strain of $P$. aeruginosa serotype 1 . The results are summarized in the table. Anti-PVA-2 and antiPVA-12 titres (not shown) were c. 20 for antibodies with these specificities.

The yield of immunoglobulin in culture supernates ranged from 25 to $94 \mu \mathrm{g} / \mathrm{ml}$ for IgG and from 3.5 to $106 \mu \mathrm{g} / \mathrm{ml}$ for IgM. Of the 18 monoclonal antibodies, 16 were specific for the immunising antigen (PVA-1) alone by ELISA, one had low-titre reactions with PVA-1, PVA-2 and PVA-12, and another had lowtitre reactions with PVA-2 and PVA-12 but not with PVA-1. Evidently, with the exception of clone no. 4, the majority of multispecific (anti-PVA-1/PVA-2/PVA12) supernates in the initial cultures arose from mixtures of hybridoma lines whose specificities segregated after cloning to obtain monoclonal cell lines. The monoclonal antibody which lacked anti-PVA-1 specificity (clone no. 18, table) did not protect mice against lethal infective challenge with the serotype-1 Pseudomonas strain. The remaining monoclonal antibodies showed various protective capacities against lethal serotype-1 pseudomonas infection, ranging from protection at a dilution of 1 in 300 (clone no. 11), to protection at dilutions of 1 in 10000 (clones nos. 2, 3, 5, 6, $9,10,14$ and 17). These highly protective antibodies 
Table I. Characterisation of monoclonal antibodies produced after immunisation with $P$. aeruginosa serotype-1 antigen extract (PVA-1)

\begin{tabular}{|c|c|c|c|c|c|}
\hline $\begin{array}{l}\text { Clone no. } \\
\text { (ES-P-1S } \\
\text { series) }\end{array}$ & $\begin{array}{c}\text { Serotype } \\
\text { specificity* }\end{array}$ & $\begin{array}{c}\text { Ig } \\
\text { isotype }\end{array}$ & $\begin{array}{l}\text { Ig concentration } \\
\text { in hybridoma } \\
\text { culture } \\
\text { supernate } \\
(\mu \mathrm{g} / \mathrm{ml})\end{array}$ & $\begin{array}{l}\text { Anti-PVA-I } \\
\text { ELISA titre }{ }^{\circ}\end{array}$ & $\begin{array}{c}\text { Protective titre } \ddagger \\
\text { of antibody } \\
\text { ( } \mu \mathrm{g} \text { of antibody/mouse) }\end{array}$ \\
\hline 1 & 1 & $\operatorname{IgG} 3$ & 90 & 1280 & $5000(0.018)$ \\
\hline 2 & 1 & IgG $2 b$ & 46 & 80 & $>10000(<0.005)$ \\
\hline 3 & 1 & IgGl & 25 & 20 & $>10000(<0.003)$ \\
\hline 4 & $1,2,12$ & $\operatorname{IgG} 1$ & 77 & 5 & $800(0.096)$ \\
\hline 5 & 1 & IgGI & 70 & 160 & $>10000(<0.007)$ \\
\hline 6 & 1 & $\mathrm{IgGl}$ & 90 & 160 & $>10000(<0.009)$ \\
\hline 7 & 1 & IgM & $3 \cdot 5$ & 320 & $800(0.004)$ \\
\hline 8 & 1 & IgM & $4 \cdot 6$ & 640 & $1000(0.005)$ \\
\hline 9 & 1 & IgG3 & 33 & 320 & $>10000(<0.003)$ \\
\hline 10 & 1 & $\operatorname{IgG} 3$ & 94 & 640 & $>10000(<0.009)$ \\
\hline 11 & 1 & IgG3 & $\ldots$ & 640 & $300 \quad \ldots$ \\
\hline 12 & 1 & IgM & $\dddot{19}$ & 320 & $800(0.024)$ \\
\hline 13 & I & IgM & 37 & 640 & $1000(0.037)$ \\
\hline 14 & 1 & IgG3 & 35 & 320 & $>10000(<0.004)$ \\
\hline 15 & 1 & IgM & 23 & 320 & $700(0.072)$ \\
\hline 16 & 1 & IgM & 106 & 640 & $700(0 \cdot 166)$ \\
\hline 17 & 1 & IgG3 & 94 & 640 & $>10000(<0.009)$ \\
\hline 18 & 2,12 & IgG 1 & 55 & 0 & $0 \quad \ldots$ \\
\hline
\end{tabular}

* Determined by ELISA screen with the 16 serotype extracts (PVAs)

$\dagger$ End-point (last positive) dilution in ELISA.

† Dilution affording complete protection against lethal challenge with $P$. aeruginosa serotype-1 strain B.UK.1.

were all IgG immunoglobulins, and included IgG1, IgG2b and IgG3 isotypes. The IgM antibodies were, in general, less protective than most of the IgG antibodies when ELISA titres were compared, but in some cases appeared to have the protective capacities approaching those of the IgG antibodies on a weight for weight comparison (table). Control culture supernates, from the NS-1 cell line and from an antibodysecreting hybrid cell line from an unrelated fusion, showed no protective capacity.

\section{Discussion}

Passive protection of mice against lethal infection by the homologous strain of $P$. aeruginosa serotype-1 was conferred by monoclonal antibodies that reacted with the immunising antigen PVA-1 in ELISA. Antibody from one clone (no. 18) failed to protect mice against infection. This antibody did not react with PVA-1 but cross-reacted with PVA-2 and PVA-12 in ELISA. Antibody from clone no. 4 cross-reacted with PVA-1, PVA-2 and PVA-12, and passively protected against infection with strain B.UK.1 although it had the lowest anti-PVA-1 ELISA titre of all in the series. The remaining antibodies were specific for PVA-1 alone in ELISA, and all were protective. The capacity of this series of monoclonal antibodies raised against $P$. aeruginosa serotype-1 antigen to cross protect against $P$. aeruginosa strains of other serotypes requires further investigation. Preliminary results have not indicated any protective capacity of the anti-PVA1 monoclonal antibodies against infection with $P$. aeruginosa serotypes other than serotype-1.

There was no distinct relationship between protective capacity, ELISA titre, immunoglobulin isotype or immunoglobulin concentration. As a generalisation, the more highly protective antibodies, affording protection at dilutions greater than 1 in 10000 , tended to be of the IgGl isotype which, conversely, tended to show low anti-PVA-1 titres in ELISA. As an example, clone no. 3 antibody is an IgG1 antibody, present at a concentration of $25 \mu \mathrm{g} / \mathrm{ml}$ in the culture supernate, that protected mice fully against the challenge at a dilution of 1 in 10000 . This was equivalent to a dose $2.5 \mathrm{ng}$ of monoclonal antibody/mouse, and of the order of 21 molecules of specific antibody for each bacterium in the challenge dose.

IgG3 antibodies showed a range of protective capacities. One IgG2b antibody was obtained which was highly protective but had a low titre in ELISA, and thus resembled the IgGI antibodies. No IgG2a antibodies were obtained. IgM antibodies showed a range of protective capacities; they were not, in general, as highly protective as some of the IgG antibodies, but two of them (clones nos. 7 and 8, possibly from sister clones) gave the same order of protection as the IgG antibodies with comparable doses. Paradoxically, the IgM and IgG3 antibodies showed the higher ELISA 
titres, indicating that the ELISA result does not predict protective capacity.

Passive protection and ELISA titres were not related to immunoglobulin concentrations. However, the vaccine antigens (PVA 1-16) are not homogeneous but are predominantly LPS (c. $95 \%$ by weight) with a minor proportion of outer-membrane proteins (OMP), and are not ideally suited for precise investigation of antibody specificities. We are currently investigating the chemical identity of the pseudomonas cell-wall antigens to which these different monoclonal antibodies bind (I.R. Poxton and G.R. Barclay, unpublished observations). Preliminary investigations by polyacrylamide gel electrophoresis antibodies and Western blotting confirm that PVA-1 specific monoclonal antibodies bind to epitopes of the polysaccharide O-antigen region of serotype-1 LPS, whereas cross-reactive monoclonal antibodies appear to bind to minor OMP (Poxton et al., 1985). The finding that anti- $P$. aeruginosa monoclonal antibodies with antiLPS activity confer passive protection while those with anti-OMP activity do not agrees with the find-

\section{REFERENCES}

Chandler H M, Cox J C, Healy K, MacGregor A, Premier R R, Hurrell J G R 1982 An investigation of the use of urease-antibody conjugates in enzyme immunoassays. Journal of Immunological Methods 53:187-194.

Davis B, Lilly H A, Lowbury E J L 1969 Gram-negative bacilli in burns. Journal of Clinical Pathology 22:634 641 .

Jones R J 1979 Antibody responses of burned patients immunized with a polyvalent pseudomonas vaccine. Journal of Hygiene 82:453-462.

Jones R J, Lilly H A, Lowbury E J L 1971 Passive protection of mice against Pseudomonas aeruginosa by serum from recently vaccinated mice. British Journal of Experimental Pathology 52:264-270.

Jones R J, Roe E A 1975 Protective properties and haemagglutinins in serum from humans and in serum from mice injected with a new polyvalent pseudomonas vaccine. British Journal of Experimental Pathology 56:34-43.

Kennett R H, Denis K A, Tung A S, Klinman, N R 1979 Hybrid plasmacytoma production: fusions with adult spleen cells, monoclonal spleen fragments, neonatal spleen cells and human spleen cells. Current Topics in Microbiology and Immunology 81:77-91. ings of Sawada et al. (1984). However, the protective capacities of the anti-LPS monoclonal antibodies of these authors were 10 - to 100 -fold less in a similar intraperitoneal protection model, and their IgM antibodies were more protective than their IgG antibodies.

Production of monoclonal antibodies against the other 15 PVAs is being done to determine their patterns of isotype production, specificity, cross-reactivity and passive protection properties against the 16 serotypes of $P$. aeruginosa. Preliminary findings indicate that monoclonal antibodies to different $P$. aeruginosa serotype extracts may differ considerably in these properties.

The hybridoma production work was supported by the Scottish Home and Health Department, Biomedical Research Committee, Grant K/MRS/50/C500 to Drs D.B.L. McClelland and K. James. We thank Dr D. Pepper for mouse IgG quantitation, $\mathrm{Mr}$ I. Hastings for mouse IgM quantification and for confirming Ig isotypes, and Professor G.D. Chisholm and Dr J.D. Cash for their encouragement.

Kohler G, Howe S C, Milstein C 1976 Fusion between immunoglobulin-secreting and non secreting myeloma cell lines. European Journal of Immunology 6:292-295.

Miler J M, Spilsbury J F, Jones R J, Roe E A, Lowbury E J, L 1977 A new polyvalent pseudomonas vaccine. Journal of Medical Microbiology 10:19-27.

Oi V T, Herzenberg L A 1980 Immunoglobulin-producing hybrid cell lines, In: Mishell B.B., Shiigi S.M. (eds) Selected methods in cellular immunology. W.H. Freeman and Co., San Francisco, pp 351-372.

Poxton I R, Bell G T, Barclay G R 1985 The association on SDS-polyacrylamide gels of lipopolysaccharide and outer-membrane proteins of Pseudomonas aeruginosa as revealed by monoclonal antibodies and western blotting. FEMS Letters (in press).

Roe E A, Jones R J 1983 Immunization of burned patients against Pseudomonas aeruginosa infection at Safdarjang Hospital, New Dehli. Reviews of Infectious Diseases Suppl 5:5922-5930.

Sawada S, Suzuki M, Kawamura T, Fujinaga S, Masuho Y, Tomibe K 1984 Protection against infection with Pseudomonas aeruginosa by passive transfer of monoclonal antibodies to lipopolysaccharides and outer membrane proteins. Journal of Infectious Diseases 150:570-576. 